\title{
Composite Consolidation Coefficient Analysis of Soft Soil with Drainage Water
}

\author{
Jihui Ding, Kaikai You, Zhongmin Feng, Dongxu Sun \\ Institute of Civil Engineering, University of Hebei, Baoding, China \\ Email: 1285043201@qq.com
}

How to cite this paper: Ding, J.H., You, K.K., Feng, Z.M. and Sun, D.X. (2019) Composite Consolidation Coefficient Analysis of Soft Soil with Drainage Water. World Journal of Engineering and Technology, 7, 572-582.

https://doi.org/10.4236/wjet.2019.74041

Received: September 9, 2019

Accepted: October 8, 2019

Published: October 11, 2019

Copyright $\odot 2019$ by author(s) and Scientific Research Publishing Inc. This work is licensed under the Creative Commons Attribution International License (CC BY 4.0).

http://creativecommons.org/licenses/by/4.0/

\section{(c) (i) Open Access}

\begin{abstract}
The consolidation coefficient is the most basic parameter to calculate the consolidation rate of soil layer, and the horizontal consolidation coefficient controls the radial water flow into the drainage well. Based on the background of the soft soil in Shantou, Guangdong Province, a series of experimental studies on the consolidation characteristics were carried out by using the modified consolidation instrument. And the concept of the composite consolidation coefficient of the drained water body was put forward. The composite consolidation coefficient reflects the consolidation characteristics of soft soil with drainage water, The test results showed that: 1) The consolidation test with drainage plate is basically consistent with the load compression curve, but its consolidation rate is fast, which is reflected by the composite consolidation coefficient. 2) In the consolidation test of water bodies with drainage, the vertical consolidation coefficient and radial consolidation coefficient are calculated by "three-point method", and then the composite consolidation coefficient is obtained. The composite consolidation coefficient decreases with the increase of drain spacing ratio, effective drainage diameter and drainage height, which is basically consistent with the theoretical formula. 3) The vertical consolidation coefficient and radial consolidation coefficient decrease with the increase of the diameter of the sample, and the difference is obvious when the load is large. The large-size model with a diameter of $100 \mathrm{~mm}$ and a height of $100 \mathrm{~mm}$ is about 1.35 times of the vertical consolidation coefficient of the conventional consolidation test.
\end{abstract}

\section{Keywords}

Blow Fill Soft Soil, Drainage Unit, Consolidation Coefficient, Consolidation Test

\section{Introduction}

Soft soil is usually formed under certain natural conditions as the environment 
changes. Due to the formation reasons and the influence of components, soft soil has high water content, large pore ratio, dark color and small permeability coefficient [1]. Its internal structure is soft and has a large compression space, which is usually in the soft plastic state or flow plastic state. Due to the influence of the region and climate of soft soil, although it shows similar external characteristics, its internal structure and composition are very different [2]. The settlement rate of soil is closely related to the consolidation characteristics of soil. The traditional consolidation test is designed on the basis of one-dimensional consolidation theory and usually adopts the method of step-by-step loading. The traditional consolidation test is simple in operation and instrument composition and is still widely used [3]. Based on the modified consolidation instrument, Lei Huayang carried out a series of experimental studies on the consolidation characteristics of soft soil filled by blowing after vacuum preloading treatment in Tianjin, focusing on the influence of sample size on the consolidation characteristics of soft soil filled by blowing [4]. Jiang Chunxia equates three-dimensional consolidation of foundation with vertical drainage to plane-strain consolidation and compares the applicability of equivalent plane-strain consolidation analysis methods [5]. Deng Yuebao [6] studied the consolidation of shaft foundation from two aspects: analytic theory and finite element method. On the one hand, the water quantity of drainage plate decreases with the increase of lateral pressure, and on the other hand, the water quantity of drainage plate decreases gradually due to the influence of bending and blockage of drainage plate. Lei Huayang [7], in order to explore the consolidation characteristics of blowing-filled ultra-soft soil and the influence rule of water content and loading ratio on the secondary consolidation coefficient, carried out the consolidation test with graded loading by using the modified low-pressure consolidation instrument and the conventional high-pressure consolidation instrument. Pei Zhusong [8] used the GDS advanced consolidation system to carry out graded loading consolidation tests on Dongting Lake soft soil. According to different drainage modes, vertical drainage consolidation tests and radial drainage consolidation tests were carried out successively, and the pore ratio, compression coefficient, compression modulus and consolidation coefficient of samples under different drainage conditions were analyzed. According to the test results, the consolidation and deformation characteristics of soil samples under different control conditions are analyzed. Menard L. [9] et al. made a simple transformation of the consolidation instrument on the basis of the conventional consolidation test, and adopted certain mechanical equipment to provide external load. Through the control of external load, the deformation rate of soil samples remained constant, and at the same time, the test effect was improved and the rigor of the experiment was increased. Chen, R.P. et al. [10] studied one-dimensional nonlinear consolidation of heterogeneous soils under instantaneous loading.

A series of laboratory consolidation tests were carried out to study the consolidation characteristics of soft soil. However, there is no direct measurement and research on the horizontal consolidation coefficient which controls the radi- 
al flow into the drainage well and the composite consolidation coefficient which contains the drainage unit. In this paper, through the automatic acquisition and displacement of the reformed large-scale consolidation instrument, the consolidation test of soft soil is carried out, and the drainage plate is added in the middle of the model, which can more intuitively reflect the actual consolidation and drainage situation of engineering, and compare and analyze with the conventional test to explore the large-size consolidation rule of drainage unit and provide reference for engineering application.

\section{Theoretical Derivation}

\subsection{Theoretical Formula of Composite Consolidation Coefficient}

The total degree of consolidation of water bodies with discharge under instantaneous loading is deduced by terzaggy theory

$$
U_{t}=1-\frac{8}{\pi^{2}} \sum_{m=1}^{m=\infty} \frac{1}{m^{2}} \mathrm{e}^{-\left(\frac{m^{2} \pi^{2} C_{v}}{4 H^{2}}+\frac{8 C_{r}}{F_{n} d_{e}^{2}}\right) t}
$$

When $U_{t}>30 \%$, the first term can be approximately taken:

$$
\begin{gathered}
U_{t}=1-\frac{8}{\pi^{2}} \mathrm{e}^{-\left(\frac{\pi^{2} C_{v}}{4 H^{2}}+\frac{8 C_{r}}{F_{n} d_{e}^{2}}\right) t} \\
F(n)=\frac{n \ln n}{n^{2}-1}-\frac{3 n^{2}-1}{4 n^{2}}, n=\frac{d_{e}}{d_{w}}
\end{gathered}
$$

where, $U_{t}$ is the average consolidation degree of vertical drainage, \%; $t$ is consolidation time, $s ; d_{\varepsilon}$ is the effective drainage diameter of the sand well, $\mathrm{cm} . H$ is the vertical drainage distance of soil layer, $\mathrm{cm} ; C_{V}$ is the vertical consolidation coefficient, $\mathrm{cm}^{2} / \mathrm{s} ; C_{r}$ is radial consolidation coefficient, $\mathrm{cm}^{2} / \mathrm{s}$.

The degree of consolidation is defined by the composite consolidation coefficient

$$
U_{t}=1-\frac{8}{\pi^{2}} \mathrm{e}^{-\frac{\pi^{2} C_{r v}}{4 H^{2}} t}
$$

where, $C_{r v}$ is the composite consolidation coefficient, and others are as above.

Contrast Equations (2) and (3):

$$
\frac{\pi^{2} C_{r v}}{4 H^{2}}=\frac{\pi^{2} C_{v}}{4 H^{2}}+\frac{8 C_{r}}{F_{n} d_{e}^{2}}
$$

From Equation (4), the ratio $\lambda$ of composite consolidation coefficient and vertical consolidation coefficient is obtained:

$$
\lambda=\frac{C_{r v}}{C_{v}}=\left(1+\frac{32 H^{2} C_{r}}{\pi^{2} F_{n} d_{e}^{2} C_{v}}\right)=\left(1+\frac{32}{\pi^{2} F_{n}} R_{H d}^{2} R_{r v}\right)
$$

where: $R_{H d}$ is the ratio between the vertical drainage distance and the radial equivalent drainage distance; $R_{r v}$ is the ratio of radial and vertical consolidation coefficient. 
From Equation (5), it can be seen that $\lambda$ is directly proportional to the square of $R_{H d}$ and directly proportional to $R_{r v}$. Figure 1 shows the relationship between $\lambda$ and $R_{H d}$ and $R_{r v}$. $\lambda$ increases with the increase of $R_{H d}$ and $R_{r v}$.

\subsection{Three-Point Method Deduced from Experimental Results}

In Figure 2, three points $\left(t_{1}, s_{1}\right),\left(t_{2}, s_{2}\right)$ and $\left(t_{3}, s_{3}\right)$ that meet the conditions are selected in the $U>30 \%$ region, and $t_{2}=2 t_{1}, t_{3}=3 t_{1}$.

Derived from Formula (2)

$$
\frac{\pi^{2} C_{v}}{4 H^{2}}+\frac{8 C_{r}}{F_{n} d_{\varepsilon}^{2}}=-\frac{1}{t_{1}} \ln \left(\frac{s_{3}-s_{2}}{s_{2}-s_{1}}\right)
$$

\section{Test Scheme}

\subsection{Experimental Materials}

The soil samples used in the test were taken from the blow filled soft soil in Shantou district, Guangdong Province. The density of the soft soil was 1.586 $\mathrm{g} / \mathrm{cm}^{3}$, the moisture content was $72.97 \%$, the initial pore ratio was 1.999 , the plastic limit was 25.4 , and the liquid limit was 51.1.

The modified WG triplex high pressure single lever consolidation instrument is used as the test instrument. The specific modified instrument is shown in Figure 3.

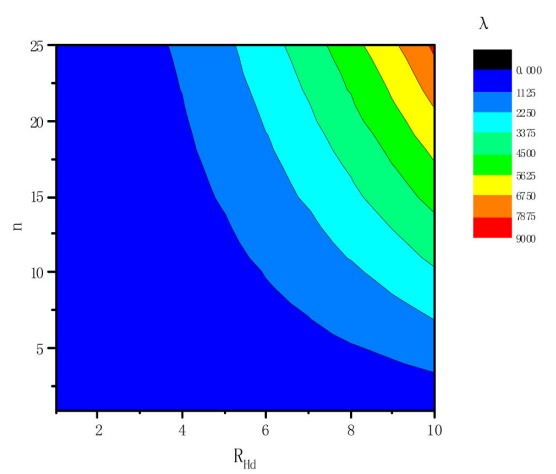

Figure 1. Relationship $\lambda$ with $\left(R_{H d}, n\right)$.

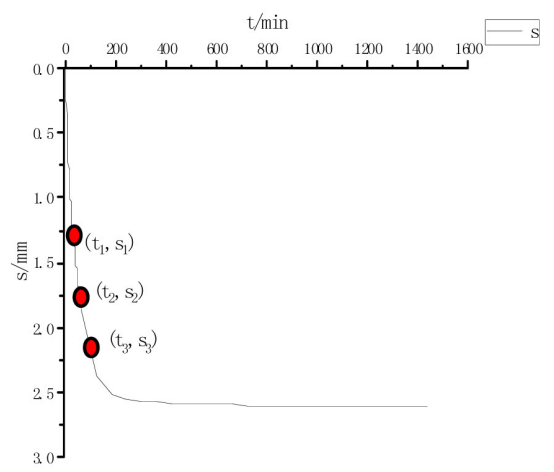

Figure 2. Relation curve between $s$ and $t$. 


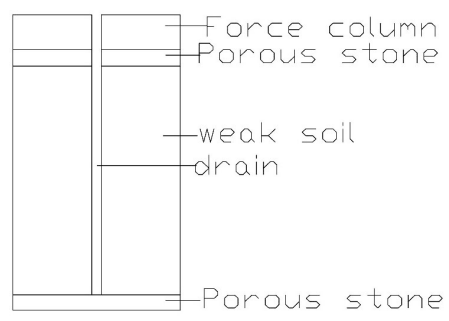

Figure 3. Consolidation instrument.

The test was carried out under the condition of normal temperature and double drainage. For each load level, the stability standard is that the deformation observed at regular intervals is less than $0.005 \mathrm{~mm} / \mathrm{d}$, and the next load is added after the deformation is stabilized under the first load. UT7116Y static strain gauge acquisition and processing system was used for data collection and recording.

\subsection{Test Scheme}

In order to study the consolidation characteristics of drainage plate added into the soft soil, and analyze the drain spacing ratio within 16 - 39, the effective drainage diameter is $80 \mathrm{~mm}, 100 \mathrm{~mm}, 120 \mathrm{~mm}$, and the drainage height is 50 $\mathrm{mm}$ and $100 \mathrm{~mm}$, respectively. Different drainage conditions and model sizes are set. The seven loading levels are $12.5 \mathrm{kPa}, 25 \mathrm{kPa}, 50 \mathrm{kPa}, 100 \mathrm{kPa}, 200 \mathrm{kPa}$, $400 \mathrm{kPa}$ and $800 \mathrm{kPa}$, respectively. The specific scheme is shown in Table 1.

\section{Analysis of Experimental Results}

\subsection{Consolidation Test Analysis of Different Drainage Channels}

The consolidation coefficient is an important parameter in Terzaghi's one dimensional consolidation theory, and its size can directly reflect the degree of soil consolidation speed. Accurately measuring the consolidation coefficient is of great significance for predicting soil drainage consolidation rate and soil consolidation degree. Through the "time square root method", the vertical consolidation coefficient of the samples without drainage plate under all levels of load and the composite consolidation coefficient of the samples with drainage plate under all levels of load were obtained. Through Formula (6), the radial consolidation coefficient $\mathrm{C}_{\mathrm{r}}$ of the samples under all levels of load was obtained.

Schemes 1 and 2, large size model with a diameter of $100 \mathrm{~mm}$ and a height of $100 \mathrm{~mm}$, with drainage plate and without drainage plate, can be compared and analyzed. According to Figure 4, it can be seen that the vertical consolidation coefficient $\mathrm{C}_{\mathrm{v}}$ and radial consolidation coefficient $\mathrm{C}_{\mathrm{r}}$ are basically the same. When the load is small, $C_{v}$ is large, and when the load is larger than $400 \mathrm{kPa}, \mathrm{C}_{\mathrm{r}}$ is large. When adding the first level of load, the vertical consolidation coefficient $\mathrm{C}_{\mathrm{v}}$ is relatively large, which may be affected by the self-weight stress. Starting from the second level of load, the consolidation coefficient gradually increases with the increase of load. The radial consolidation coefficient first increases and 


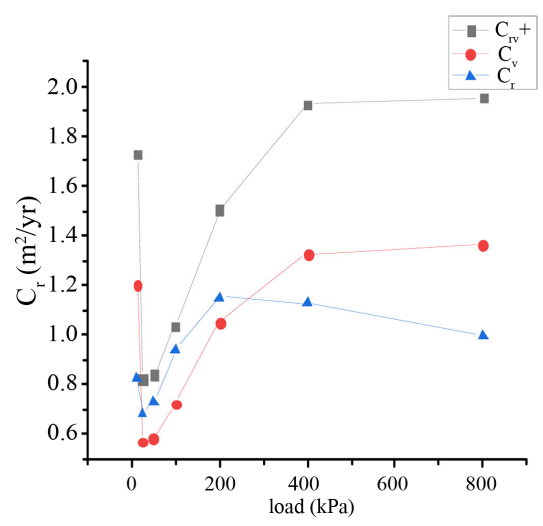

Figure 4. Relation between consolidation coefficient and load.

Table 1. Test scheme.

\begin{tabular}{ccccc}
\hline Serial number & Model size & Drainage way & Set drainage water & Drain spacing ratio \\
\hline 1 & $\Phi 100 \mathrm{~mm}$ & Double vertical & - & - \\
2 & $\Phi 100 \mathrm{~mm}$ & Double vertical and radial & $6 \mathrm{~mm}$ wide & 20 \\
3 & $\Phi 100 \mathrm{~mm}$ & Double vertical and radial & $2 \mathrm{~mm}$ wide & 39 \\
4 & $\Phi 100 \mathrm{~mm}$ & Double vertical and radial & $4 \mathrm{~mm}$ wide & 26 \\
5 & $\Phi 100 \mathrm{~mm}$ & Double vertical and radial & $8 \mathrm{~mm}$ wide & 16 \\
6 & $\Phi 80 \mathrm{~mm}$ & Double vertical & - & - \\
7 & $\Phi 120 \mathrm{~mm}$ & Double vertical & - & - \\
8 & $\Phi 80 \mathrm{~mm}$ & Double vertical and radial & $4.3 \mathrm{~mm}$ wide & 20 \\
9 & $\Phi 120 \mathrm{~mm}$ & Double vertical and radial & $7.2 \mathrm{~mm}$ wide & 20 \\
10 & $\Phi 100 \mathrm{~mm}$ & Single vertical & $6 \mathrm{~mm}$ wide & 20 \\
11 & $\Phi 100 \mathrm{~mm}$ & Single vertical and radial & $6 \mathrm{~mm}$ wide & 20 \\
\hline
\end{tabular}

then decreases with the increase of load. It may be that with the increase of load, the consolidation of soft soil goes deep, leading to deformation and blockage of drainage plate, thus affecting the radial consolidation coefficient. At $400 \mathrm{kPa}, \mathrm{C}_{\mathrm{v}}$ is $1.33 \mathrm{~m}^{2} / \mathrm{yr}$, and $\mathrm{C}_{\mathrm{rv}}$ is $45 \%$ larger than $\mathrm{C}_{\mathrm{v}}$. The $\mathrm{C}_{\mathrm{rv}} / \mathrm{C}_{\mathrm{v}}$ under each level of load is 1.4 times, which is basically consistent with the value of 1.37 times obtained by Formula (5). The addition of drainage plates reduces the drainage distance and speeds up the consolidation rate.

\subsection{Analysis of Drainage Consolidation Test Results with Different Well Diameter Ratios}

Through the scheme 2 - 5 to simulate the model size for $\Phi 100 \mathrm{~mm}$ drainage consolidation test, the width of drainage board is $2 \mathrm{~mm}, 4 \mathrm{~mm}, 6 \mathrm{~mm}$ and $8 \mathrm{~mm}$ respectively. That is, the drain spacing ratio $\mathrm{n}$ is $39,26,20$ and 16 respectively. According to Figure 5, consolidation tests of different drain spacing ratio show that the consolidation coefficient changes with load in basically the same way. As the drainage diameter increases, the composite consolidation coefficient of the 


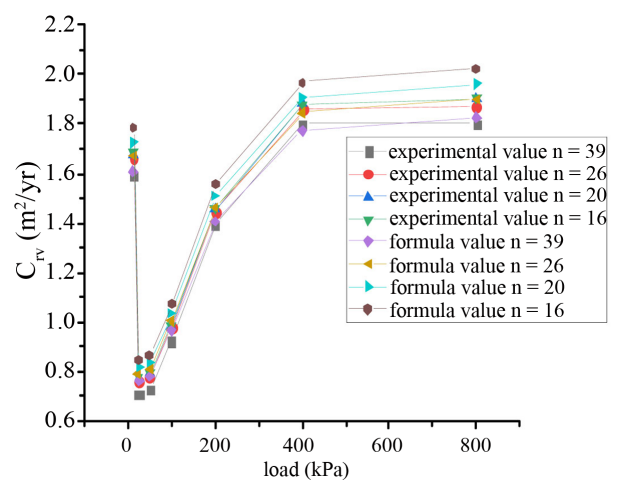

Figure 5. Relationship between composite consolidation coefficient $\mathrm{C}_{\mathrm{rv}}$ and load $\mathrm{p}$.

test increases slightly. When the drain spacing ratio is 39 , the experimental value is basically consistent with the results obtained by Formula (5). When the drain spacing ratio is 26,20 and 16 , the formula value is slightly larger than the test value. The main reason for the test is that the model size is small, the effect of drain spacing ratio on the composite consolidation coefficient is small, and the vertical consolidation coefficient has no effect basically. As can be seen from Figure 6, the radial consolidation coefficient $C_{r}$ first increases and then decreases with the increase of load. With the increase of drain spacing ratio, $n$ equals 39 over $\mathrm{n}$ equals 16 decreases by $0.17 \mathrm{~m}^{2} / \mathrm{yr}$ at $200 \mathrm{kPa}$, while other loads change little.

\subsection{Analysis of Drainage Consolidation Test Results of Different Sizes}

Schemes 6 - 9 were used to study the $C_{v}$ of samples with different diameters without adding drain plate, and $\mathrm{C}_{\mathrm{rv}}$ of samples with different diameters with adding drain plate. Through Formula (5), the radial consolidation coefficient $\mathrm{C}_{\mathrm{r}}$ of samples with different diameters under various loads was obtained, and compared with conventional consolidation tests.

As can be seen from Figure 7, in the soft soil consolidation test with drainage plate, with the same drain spacing ratio, the larger the effective diameter of drainage is, the smaller the composite consolidation coefficient $\mathrm{C}_{\mathrm{rv}}$ of soft soil is, that is, the consolidation rate of soft soil is getting smaller and smaller, greatest difference when $400 \mathrm{kPa}, \Phi 8 \mathrm{~cm}$ is about $0.88 \mathrm{~m}^{2} / \mathrm{yr}$ higher than $\Phi 10 \mathrm{~cm} \mathrm{C}$, increased by $58 \%$. So engineering with "thin and dense" drainage sand Wells.

To the sample of different diameter, the changing rule of the coefficient of consolidation is roughly same; to the sample of different diameter, the vertical coefficient of consolidation and radial consolidation coefficient decreases with increasing the diameter of the sample. As shown in Figure 8, there was a large difference at the load of $400 \mathrm{kPa}$, and the $\mathrm{C}_{\mathrm{r}}$ of $\Phi 8 \mathrm{~cm}$ was about $0.098 \mathrm{~m}^{2} / \mathrm{yr}$ higher than that of $\Phi 10 \mathrm{~cm}$. This is because the increment of excess pore water pressure in soil body is the same under the same load increment, but the effective diameter of drainage increases with the increase of soil sample diameter. 


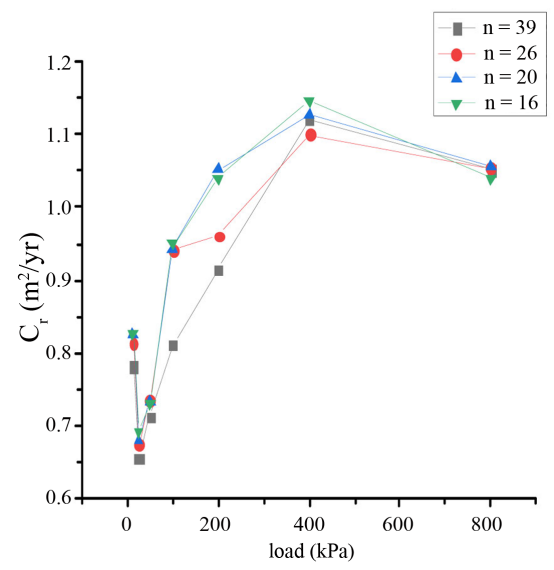

Figure 6. Relation between radial consolidation coefficient $C_{r}$ and load $p$.

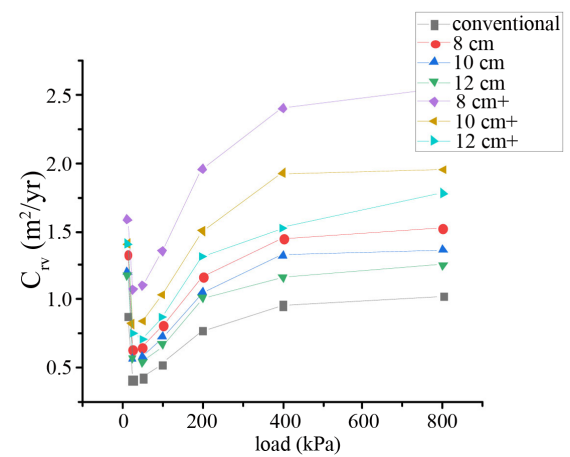

Figure 7. Relation between consolidation coefficient $C$ and load p.

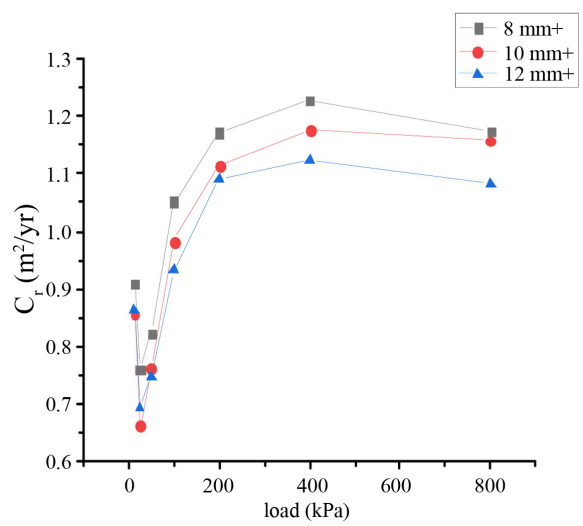

Figure 8. Relation between radial consolidation coefficient $\mathrm{C}_{\mathrm{r}}$ and load $\mathrm{p}$.

Therefore, the drainage consolidation speed decreases with the increase of soil sample diameter, especially the soil sample with drainage plate, that is, the consolidation coefficient decreases with the increase of effective drainage diameter of soil sample.

The large-size model of $100 \mathrm{~mm}$ is larger than the $\mathrm{C}_{\mathrm{v}}$ of conventional consolidation test, and the difference is the largest at $800 \mathrm{kPa}$. The average value of $\mathrm{C}_{\mathrm{v}}$ under different loads differs by $0.25 \mathrm{~m}^{2} / \mathrm{yr}$, which is about $35 \%$ of the conventional consolidation coefficient. It is concluded that the test results of conven- 
tional soil samples cannot be used in practical engineering, and the effect of size effect on the results should be fully considered.

\subsection{Consolidation Coefficient Analysis of Single and Double Drainage}

The effects of single drainage and double drainage on consolidation coefficient are studied in Schemes 10 - 11. According to Figure 9, under the condition of consolidation without drainage plate, the vertical consolidation coefficient $\mathrm{C}_{\mathrm{v}}$ of single and double drainage decreases first and then gradually increases with the increase of consolidation pressure $p$, but the curves of the two drainage conditions are intersecting. That is, when the consolidation pressure is less than 200 $\mathrm{kPa}$, the consolidation coefficient under double-sided drainage condition is larger than that under single-sided drainage condition, while when the consolidation pressure is more than $200 \mathrm{kPa}$, the situation is just the opposite. When drainage plate is added, the composite consolidation coefficient $\mathrm{C}_{\mathrm{rv}}$ of single drainage is larger than that of double drainage. With the increase of drainage height, the effect of adding drainage plate on improving consolidation rate increases obviously. According to Figure 10, the radial consolidation coefficient $\mathrm{C}_{\mathrm{r}}$ of double-sided drainage is basically the same as that of single-sided drainage when the load is relatively small. When the load is greater than $200 \mathrm{kPa}$, the radial consolidation coefficient $\mathrm{C}_{\mathrm{r}}$ of double-sided drainage is larger than that of single-sided drainage.

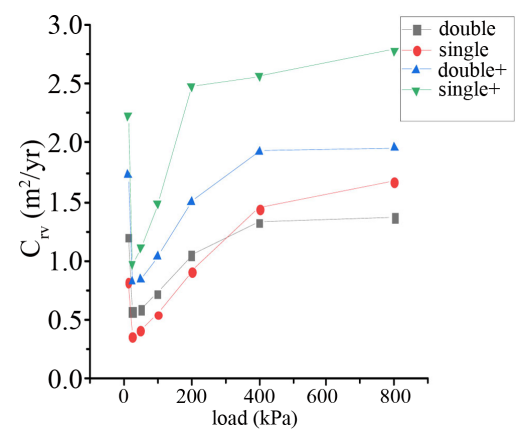

Figure 9. Relation between consolidation coefficient $\mathrm{C}_{\mathrm{rv}}$ and load $\mathrm{p}$.

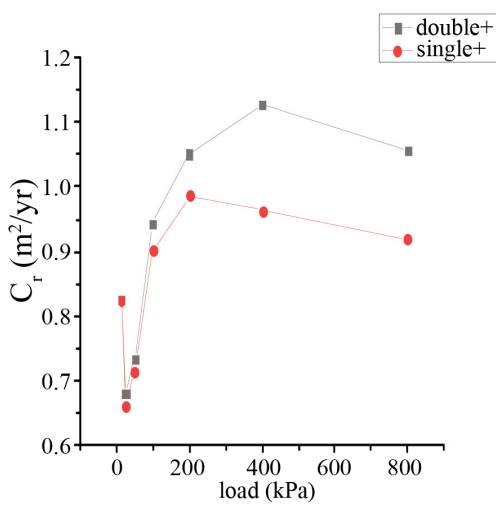

Figure 10. Relation between radial consolidation coefficient $\mathrm{C}_{\mathrm{r}}$ and load $\mathrm{p}$. 


\section{Conclusions}

1) The consolidation test with drainage plate has basically the same change law of load compression curve as that without drainage plate, but its consolidation rate is fast. Composite consolidation coefficient is used to reflect the effect of adding drainage plate, so as to comprehensively reflect the consolidation rate.

2) In the consolidation test with drainage plate, the vertical consolidation coefficient and radial consolidation coefficient are calculated by "three-point method", and then the composite consolidation coefficient is obtained. The composite consolidation coefficient decreases with the increase of the drain spacing ratio, effective drainage diameter and drainage height, which is basically consistent with the theoretical formula.

3) The consolidation coefficient changes in samples with different diameters in roughly the same way. The vertical consolidation coefficient and radial consolidation coefficient decrease with the increase of the diameter of the sample, and the difference is obvious when the load is large. The vertical consolidation coefficient of the samples with different borehole diameter ratio is basically the same, while the radial consolidation coefficient decreases slightly. Compared with double drainage and single drainage, the vertical consolidation coefficient increases first and then decreases with the increase of load, while the radial consolidation coefficient decreases when the load is greater than $400 \mathrm{kPa}$. The large-size model with a diameter of $100 \mathrm{~mm}$ and a height of $100 \mathrm{~mm}$ is about 1.35 times the vertical consolidation coefficient of conventional consolidation test. The influence of size effect on results should be fully considered in engineering.

\section{Conflicts of Interest}

The authors declare no conflicts of interest regarding the publication of this paper.

\section{References}

[1] Chen, X.P. (2017) Consolidation Effect of Soft Soil Deposited by Sea and Land Interchanges. Journal of Geotechnical Engineering, 33, 520-528.

[2] Dong, Z.L. and Zhang, G.X. (2018) Research and Development and Application of Consolidation Technology of Shallow Supersoft Soil in Tianjin Binhai New Area. Journal of Rock Mechanics and Engineering, 30, 1074-1080.

[3] Yin, C.Q. (2017) Study on Strengthening Characteristics of Tianjin Port Ultra-Soft Soil Foundation. Journal of Geotechnical Engineering, 39, 122-125.

[4] Lei, H.Y., He, C.F., Qiu, W.W. and Chen, L. (2016) Experimental Study on the Effect of Size Effect on Consolidation Characteristics of Soft Soil Filled by Blowing. Journal of Tianjin University (Natural Science and Engineering Technology Edition), 49, 73-79.

[5] Jiang, C.X. (2005) Axisymmetric Consolidation and Plane Strain Equivalent Consolidation Analysis of Foundation with Vertical Drainage. Hohai University, Nanjing. 
[6] Deng, Y.B. (2013) Analytical Theory and Finite Element Analysis of Shaft Foundation Consolidation. Zhejiang University, Hangzhou.

[7] Lei, H.Y., Ren, Q., Zhang, W.Z., Huang, M.S. and Kang, J.W. (2014) Experimental Analysis of Consolidation Characteristics of Blow-Filled Super Soft Soil. Journal of Engineering Geology, 22, 1039-1045.

[8] Pei, Z.S. (2017) Study on Consolidation Characteristics of Soft Soil in Dongting Lake area. University of Science and Technology of Hunan, Xiantang.

[9] Menard, L. and Broise, Y. (2014) Theoretical and Practical Aspects of Dynamic Consolidation. Geotechnique, 25, 3-18. https://doi.org/10.1680/geot.1975.25.1.3

[10] Chen, R.P., Zhou, W.H., Wang, H.Z. and Chen, Y.M. (2005) One-Dimensional Nonlinear Consolidation of Multi-Layered Soil by Differential Quadrature Method. Computers and Geotechnics, 32, 358-369.

https://doi.org/10.1016/j.compgeo.2005.05.003 